\title{
Inspiratory times when weaning from mechanical ventilation
}

\author{
A GREENOUGH, F GREENALL, AND H R GAMSU
}

Department of Child Health, King's College Hospital, London

\begin{abstract}
SUMMARY Two inspiratory times $(0.5$ and 1.0 seconds) were compared when weaning infants from mechanical ventilation. The shorter inspiratory time was associated with significant increases in minute volume and reduction in active expiration.
\end{abstract}

The interaction of an infant's spontaneous respiration and intermittent positive pressure ventilation can be an important determinant of outcome; infants who actively breathe out develop pneumothoraces. ${ }^{1}$ Both active breathing out ${ }^{2}$ and pneumothoraces ${ }^{3}$ are more common in infants ventilated with prolonged inspiratory times. Fast rate ventilation (more than 60 breaths/minute) during which the inspiratory time is shortened, reduces the incidence of active breathing out ${ }^{4}$ and pneumothoraces. ${ }^{5}$

As the infant is weaned from ventilation the rate is often reduced by increasing both the inspiratory time and expiratory time until the inspiratory time is increased to one second. This increase could stimulate active breathing out and reduce the effectiveness of positive pressure inflation, and might even be responsible for the late occurrence of pneumothoraces. At ventilator rates of $60 /$ minute the inspiratory time is about 0.5 seconds, and infants tend to breathe synchronously, ${ }^{1}$ an interaction likely to produce optimum gas exchange. ${ }^{6}$ We therefore investigated the hypothesis that a more appropriate method of weaning infants from fast rate ventilation would be to keep the inspiratory time constant at 0.5 seconds and to reduce the rate by extending only the expiratory time.

\section{Patients and methods}

Ten infants were entered into the study; the mean gestational age was 30.1 weeks (range 27-36) and the mean postnatal age 4.3 days (range $3-7$ ). All were receiving assisted ventilation for the respiratory distress syndrome via oral endotracheal tubes using Sechrist ventilators.

Permission for this study was given by the hospital ethical committee.

Infants were entered into the study when their respiratory distress syndrome had improved to the extent that at a ventilator rate of $60 /$ minute and an inspiratory time of 0.5 seconds the peak inflating pressure could be reduced to $20 \mathrm{~cm} \mathrm{H}_{2} \mathrm{O}$ or below. Subsequently no reduction in the peak inflating pressure was made, and the ventilator rate was reduced by increasing only expiratory time, the inspiratory time remaining constant at 0.5 seconds throughout. Examples of ventilator settings are: 40 breaths/minute, inspiratory time 0.5 seconds, expiratory time 1.0 seconds; 20 breaths/minute, inspiratory time 0.5 seconds, expiratory time 2.5 seconds.

During weaning, at ventilator rates of both 20 and 40 breaths/minute inspiratory time was temporarily increased (for 20 minutes) from 0.5 to 1.0 seconds. It was therefore possible to study the infant at two different inspiratory times during weaning. At each ventilator setting recordings were made of transcutaneous oxygen, volume exchange, and the infant's spontaneous respiratory interaction by the method previously described in detail. ${ }^{14}$

Transcutaneous oxygen tension was monitored throughout the study. Transcutaneous oxygen tensions were reported as the mean of the results of the final five minute period at each inspiratory time and ventilator rate. We analysed the respiratory recordings after a period of up to two minutes had been allowed at each inspiratory time and ventilator rate for the infant to adjust to the new setting. Inflating volume was defined as the volume of gas delivered during positive pressure inflation. Spontaneous respiratory rate and tidal volume were recorded between each positive pressure inflation. Minute volume was calculated as the volume of gas delivered in one minute by both mechanical ventilation and spontaneous respiration. From the recordings at each rate and inspiratory time the amount of active breathing out was determined. ${ }^{4}$

At an inspiratory time of 0.5 and 1.0 seconds and at both ventilator rates the significance of differences in volume exchange was calculated using the Wilcoxon rank sum test. The significance of differences in the presence of active breathing out was calculated using Fisher's exact test.

\section{Results}

The inflating volumes were not significantly different at the two inspiratory times at either ventilator rate. When the inspiratory times of 0.5 and 1.0 seconds were compared at both rates there were no 
Table Volume exchange at different inspiratory times (expressed as mean values of 10 patients)

\begin{tabular}{|c|c|c|c|c|}
\hline \multirow[t]{2}{*}{ Ventilator rate } & \multicolumn{2}{|c|}{$\begin{array}{l}\text { Inspiratory time at } 40 \text { breaths/minute } \\
\text { (seconds) }\end{array}$} & \multicolumn{2}{|c|}{$\begin{array}{l}\text { Inspiratory time at } 20 \text { breaths/minute } \\
\text { (seconds) }\end{array}$} \\
\hline & 0.5 & 1.0 & 0.5 & 1.0 \\
\hline $\begin{array}{l}\text { Inflating volume }(\mathrm{ml}) \\
\text { Spontaneous respiratory }\end{array}$ & $13 \cdot 1$ & $13 \cdot 8$ & $10 \cdot 8$ & $11 \cdot 3$ \\
\hline $\begin{array}{l}\text { Spontaneous respiratory } \\
\text { rate (minute) } \\
\text { Spontaneous tidal }\end{array}$ & $53 \cdot 3$ & $16 \cdot 1$ & $43 \cdot 7$ & $16 \cdot 3$ \\
\hline $\begin{array}{l}\text { volume }(\mathrm{ml}) \\
\text { Minute volume }\end{array}$ & $4 \cdot 1$ & $2 \cdot 1$ & $3 \cdot 0$ & $2 \cdot 7$ \\
\hline$(\mathrm{ml})$ & 750 & 628 & 436 & 373 \\
\hline
\end{tabular}

significant differences in the spontaneous tidal volumes, but spontaneous respiratory rates $(\mathrm{p}<0.01)$ and minute volume $(\mathrm{p}<0.05)$ were significantly greater at the shorter inspiratory time (table).

Transcutaneous oxygen tensions were similar in four infants at the two inspiratory times but in six were higher at the shorter inspiratory time showing a change in oxygenation of greater than $1.33 \mathrm{kPa}$. In those infants actively breathing out at an inspiratory time of 1.0 seconds oxygenation improved at the shorter inspiratory time. At both rates only one infant made active efforts to breathe out at an inspiratory time of 0.5 seconds, but at the longer inspiratory time seven of the 10 infants did so $(\mathrm{p}<0 \cdot 02)$.

No infant required a change in peak inflating pressure or ventilator rate, or developed a pneumothorax once weaning had started.

\section{Discussion}

The shorter inspiratory time $(0.5$ seconds) was not associated with a significant reduction in inflating volume; there are two possible explanations for this. Firstly, at the longer inspiratory time most of the infants breathed out before the end of positive pressure inflation, thereby limiting volume exhange. Secondly, although the infants were recovering from respiratory distress syndrome, their lungs were still non-compliant with a reduced time constant, thus 0.5 seconds was long enough to complete volume exchange.

Maintaining a shorter inspiratory time by increasing the time between positive pressure inflations permitted increased respiratory activity, which in turn significantly increased the minute volume, thereby improving gas exchange. Another important advantage of the shorter inspiratory time was that fewer infants actively breathed out.

These results suggest that a shorter inspiratory time may be advantageous and it appears to be safe. It is now important to compare the efficacy of the two methods. We have therefore embarked on a randomised study to assess if (as we predict from these results) the length of weaning is reduced if the inspiratory time is limited to 0.5 seconds.

Sister F Greenall was supported by Bearcub International. Children Nationwide Medical Research Fund generously provided the equipment used in this study. We thank Mrs A McPherson for secretarial assistance.

\section{References}

${ }^{1}$ Greenough A, Morley CJ, Davis JA. Interaction of spontaneous respiration with artificial ventilation in preterm babies. J Pediatr 1983;103:769-73.

${ }^{2}$ Greenough A. The premature infant's respiratory response to mechanical ventilation. Early Hum Dev (in press).

${ }^{3}$ Primak PA. Factors associated with pulmonary air leak in premature infants receiving mechanical ventilation. $J$ Pediatr 1983;102:764-8.

${ }^{4}$ Greenough A, Morley CJ, Pool J. Fighting the ventilator - are fast rates an effective alternative to paralysis? Early Hum Dev 1986;13:189-94.

${ }^{5}$ Pohlandt F, Beinsau V, Fielen KD, et al. Reduction in barotrauma in ventilated infants by increase in ventilation frequency. First results of a prospective collaborative and randomised trial of two different ventilator techniques. Pediatr Res 1985;19:1077.

${ }^{6}$ Greenough A, Pool J, Greenall F, Morley CJ, Gamsu H. Comparison of different rates of artificial ventilation in preterm neonates with the respiratory distress syndrome. Acta Paediatr Scand 1987;76:706-12.

Correspondence to Dr A Greenough, Department of Child Health, King's College Hospital, London SE5 8RX.

Received 12 June 1987 